\title{
On English Translation of Chinese Original Picture Books from the Perspective of Multimodality
}

\author{
Yinjuan Chu \\ College of Humanities, Tianjin Polytechnic University, Tianjin, China \\ Email: 2409282764@qq.com
}

How to cite this paper: Chu, Y.J. (2020) On English Translation of Chinese Original Picture Books from the Perspective of Multimodality. Open Access Library Journal, 7: e6208.

https://doi.org/10.4236/oalib.1106208

Received: March 4, 2020

Accepted: March 16, 2020

Published: March 19, 2020

Copyright () 2020 by author(s) and Open Access Library Inc.

This work is licensed under the Creative Commons Attribution International License (CC BY 4.0).

http://creativecommons.org/licenses/by/4.0/

\section{(c) (i)}

Open Access

\begin{abstract}
Going global of China's original picture books with distinctive multimodal features constitutes an important link in spreading Chinese culture. Taking the multimodal discourse analysis of Chinese original picture books $A \mathrm{NeW}$ Year's Reunion, The Red Shoe and First Trip away from Home as examples, the present article makes a tentative study on strategies for English translation of Chinese original picture books from three perspectives, namely taking both texts and pictures into consideration, making it possible for readers to be aesthetically entertained during reading, and showing respect for cultural difference. In this way, multimodality provides a feasible and insightful approach for cultural transmission and reproduction of childish delight in the field of text-picture mutual construction.
\end{abstract}

\section{Subject Areas}

Linguistics

\section{Keywords}

Multimodality, Chinese Original Picture Books, Childish Delight, English Translation

\section{Introduction}

Fine literary works reflect the cultural creativity of a nation, and they are essential not only for attracting and enlightening people but also for Chinese culture going global. The Chinese original picture book, characterized by its multimodal narrative form of the image and text to tell Chinese stories, serves as a bridge to spread Chinese culture. Therefore, it is of critical importance to bring Chinese 
original picture books to the world.

\section{Multimodality and the Research Status of Chinese Original Picture Books}

Nowadays, owing to the rapid progress of technology, approaches to convey meanings are no longer confined to the verbal text only. On the contrary, other semiotics like images, gestures, sounds and even music are gaining their popularity in communication such as in newspaper reports and advertisement on account of their multimodal nature. Under the circumstances, multimodal discourse analysis turns out to be essential for the analysis of how meanings are realized in discourses where communication is realized by more than one mode.

Western scholars have begun to be alert to multimodal discourse analysis since the 1990s, making major breakthroughs in the study of multimodal discourse analysis. Its central tenet is that messages can be produced by various semiotic modes like sound, images, gestures, and graphics apart from language. In 2003, the scholar Li Zhanzi firstly offers a general overview of the grammar of visual design raised by Gunther Kress and Theo Van Leeuwen, marking the introduction to multimodal discourse analysis into China. From 2003 onwards, various associated studies have been carried out [1] [2]. Among them, there are studies on the relationship between graphics and texts and how different modes work together by giving full play of their advantages to tell stories. Zhu Yongsheng (2007) believes that there are two criteria to identify multimodality, namely the number of types of modes involved and the number of symbolic systems involved [3]. Although only one mode is involved in some discourses, two or more symbolic systems are contained, however. The comic is an instance. Even if it only involves visual mode, but it is also regarded as multimodal discourse because it tells the story with both text and pictures. He also observes that the significance of multimodal discourse analysis is that it can integrate language with other related meaning resources. Thus, the discourse can be interpreted. However, little regard has been paid to the study of Chinese original picture books, a typical kind of multimodal text.

In the 1950s, a large number of excellent picture books from the Soviet Union and Europe and the United States were translated into Chinese in China, which lays the prototype of Chinese picture books in the course of the introduction and study of foreign picture books. The 1970s, when numerous illustrators emerged, saw the beginning of the Chinese original picture books. In the 1990s, painters' adaptation of Chinese folktales, legends, and fables into picture books provided the rich experience for the creation of Chinese original picture books, which marked the development of Chinese original picture books. Since the beginning of the 21 st century, with the introduction of copyrights of more foreign picture books, Chinese people have been longing for creating original Chinese picture books, leading to the remarkable improvement in the creation of local picture books. During this period, some picture books such as $A$ New Year's Reunion are published successively and are translated into various languages. However, 
Chinese original picture books fail to be attached enough importance in translation studies, and few profound studies have been conducted on their English translation.

Therefore, this paper using the theory of multimodal discourse analysis makes a tentative study on them from the perspective of the English translation, which will surely enrich the area of research on multimodal discourse analysis to some extent.

\section{English Translation Strategies for Chinese Original Picture Books from a Multimodal Perspective}

The picture book involves two symbolic systems of language and image. Therefore, in order to create excellent translations, three dimensions are supposed to be both taken into account in the process of translating the Chinese original picture book, namely expressing its nature of multimodality and entertaining readers of target languages, and taking culture into consideration. For one thing, on the basis of correct interpretation of images, it is imperative to combine the text with images and take advantage of their strengths so that the translated work is loyal to the source text both in content and emotion. And for another, the target audience of the picture book is mainly children, which requires that the translator should reproduce childish delight and simplicity through various approaches to ensure that readers will be aesthetically entertained. To be specific, the English translation of the picture book can be attempted from the following three perspectives.

\subsection{Exploiting the Multimodal Nature of Chinese Original Picture Books}

\subsubsection{Choosing Words on the Basis of Precise Interpretation of Pictures} As a bridge to promote mutual understanding between different nations and languages, the primary function of translation is conveying information so that the target audience can grasp general information expressed in the original. Therefore, in the process of translation, attention should be paid to accuracy first, and the translator should do his best to translate the original under the guidance of grammar, syntax, and lexicon. As children are the primary implied audience of the picture book, the author tends to utilize expressions and sentences easy to understand, and the illustrator is dedicated to making pictures vivid and attractive. Although synonyms are ubiquitous in English, there is subtle nuance in their meanings, to which special attention needs to be paid in the process of translating. During translation, the translator should put himself in the author's and illustrator's shoes and read pictures thoroughly without any details overlooked. Only in this way can present readers the work retaining the taste of the original. A scene in $A$ New Year's Reunion where Maomao stood in the distance waiting for the father presents the mentality of a left-behind child vividly, making readers vicariously share the same experience and the subtle emotions of the father and daughter (seeing Figure 1). 


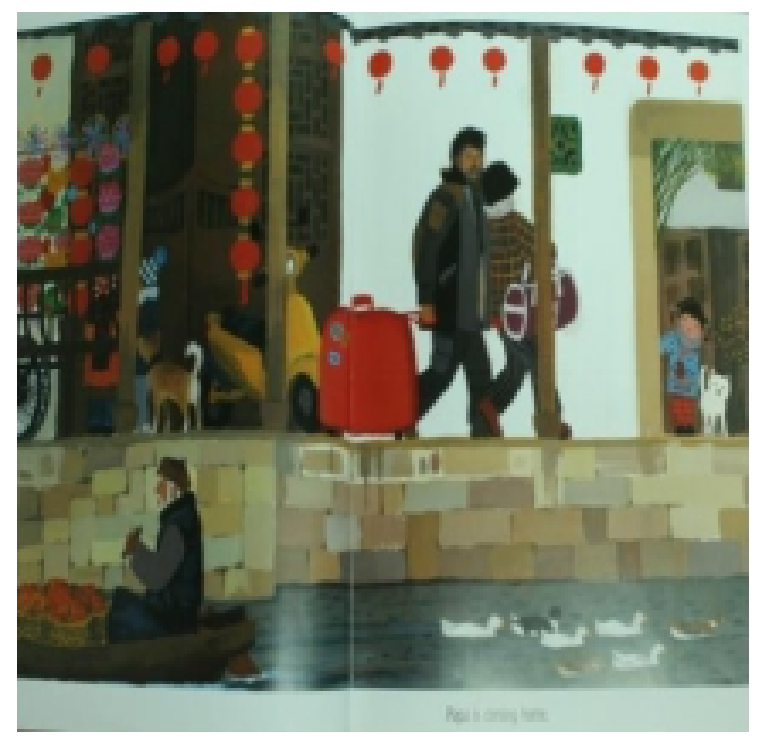

Figure 1. The father's return.

Traveling all year round, the father can spend little time with the family. For a child, it is no wonder that Maomao feels so strange to her father that she refuses to come near to the father, which is vividly presented by pictures (seeing Figures 1-3). This can be evidenced by the photo frame hung on the wall. In Figure 2, only Maomao and her mother appear in the photograph and she stands far away from her father. In the beginning, when the father just arrives at home, the father is absent from the picture frame, which is hung in the bedroom. However, after getting along with the family, the father appears in the family photo when he is leaving at the end of the story. These details imply that Maomao cannot even remember what his father is like after a long separation and feels strange to the father. These details seem to be not as important as the text, but they do exert an overarching influence in selecting proper words to translate the original. Providing that the expression "Bu ken" in the source text here is translated verbatim into "not willing" or "not want", its translation will diverge from the emotion expressed by the original. According to pictures, although Maomao does not greet her father with her mother, she keeps hiding behind her door with her kitten and looking at her father from afar. A picture in which the little girl cranes her neck to see where the father is and when he will arrive comes into the reader's mind (seeing Figure 1). This shows that Maomao is full of expectation for the father's return. Based on the correct interpretation of pictures and deep exploration of the relationship between pictures and the text, the translator translates it into "not daring". In this way, the translation "not daring" not only is highly equivalent to the original in content but also reflects the mentality of left-behind children like Maomao in China who love their parents deeply even if they seem to be afraid of their parents (seeing Figure 4 and Figure 5).

As Finnish writer and translator of children's literature Rita Ottinnen said, "When translating picture books, where illustration is an essential element of the 


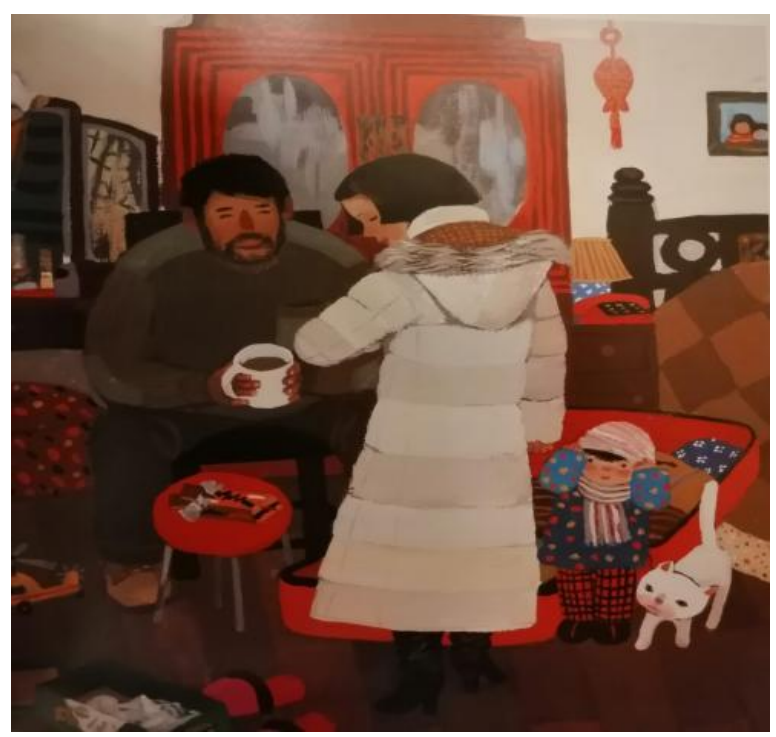

Figure 2. The appearance of two people in the picture frame.

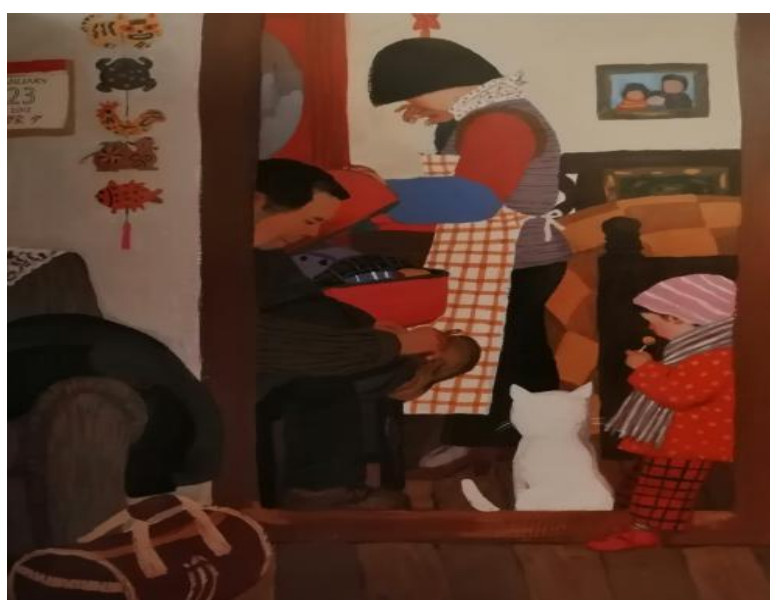

Figure 3. The appearance of three people in the picture frame.

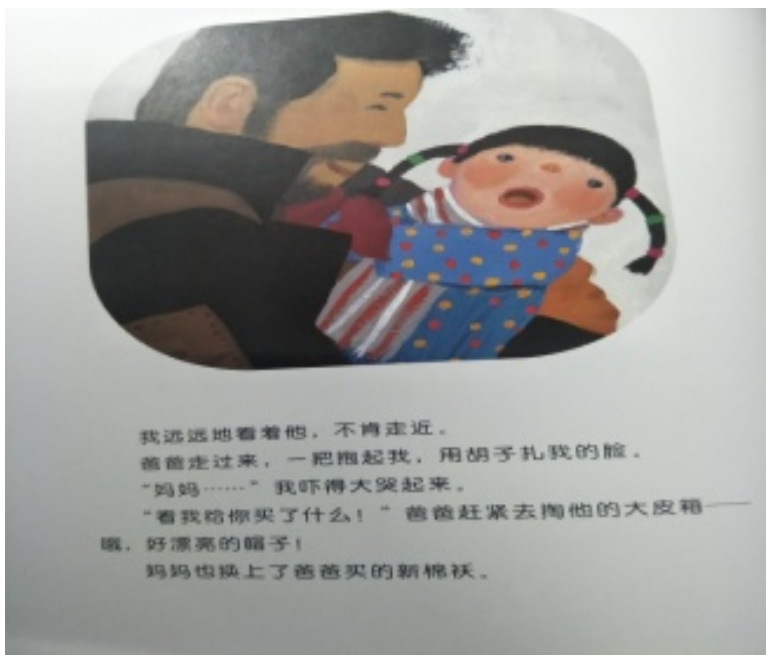

Figure 4. Chinese description of Maomao's attitude to the father. 


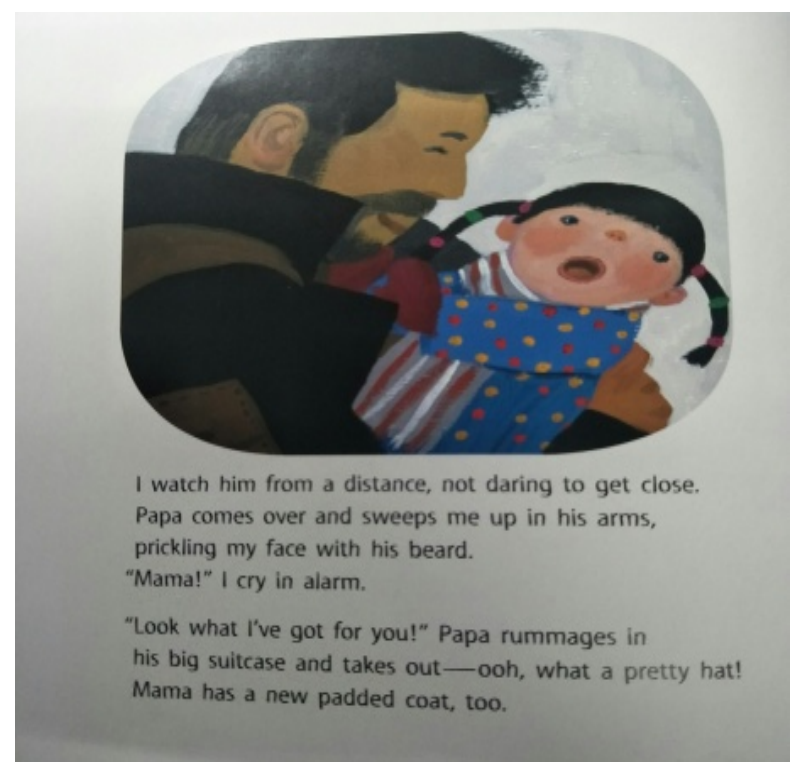

Figure 5. English description of Maomao's attitude to the father.

story, translators need to have the ability to read pictures, too, in the same way as they need the ability to read and write foreign written and spoken language." (Oittinen 2000: 101) [4].

\subsubsection{Giving Priority to Context and Considering Both Pictures and Text} Newmark believes "Communicative translation attempts to produce on its readers an effect as close as possible to that obtained on the readers of the original. Semantic translation attempts to render, as closely as the semantic and syntactic structures of the second language allow, the exact contextual meaning of the original" (Newmark 1981: 39) [5]. In the process of translating, the translator needs to read pictures correctly and to attach great importance to the whole context built by visual mode and verbal mode as well so as to fully understand the meaning of the original and convey its meaning to the reader. The expression that "Da nian chu san, xia xue le, xia de hao da hao da" in $A N e w Y^{2} a r ' s$ Reunion is an instance (Figure 6).

When it comes to the degree of something, Chinese is accustomed to adopting repetition, while English is used to using adverbs. In this sentence, to emphasize the heavy snow, the original repeats the phrase "Hao da" twice. However, the translation is "really hard" rather than "really hard, really hard". This kind of translation complies with the tradition of English. There are three sentences for this part, and the first sentence is illustrated with one picture. It can be seen that white, the symbol of snow, is the predominant hue in Figure 6 and Figure 7. The picture where the roof and parapet are drawn with thick lines is densely scattered with big white spots, showing readers a picturesque snowy landscape and compensating for the translation. "Picture books are unified artistic whole in which text and picture, cover and end page, and the details of design work together to provide an aesthetically satisfying experience" (Lawrence 1998: 97, my own translation) [6]. 


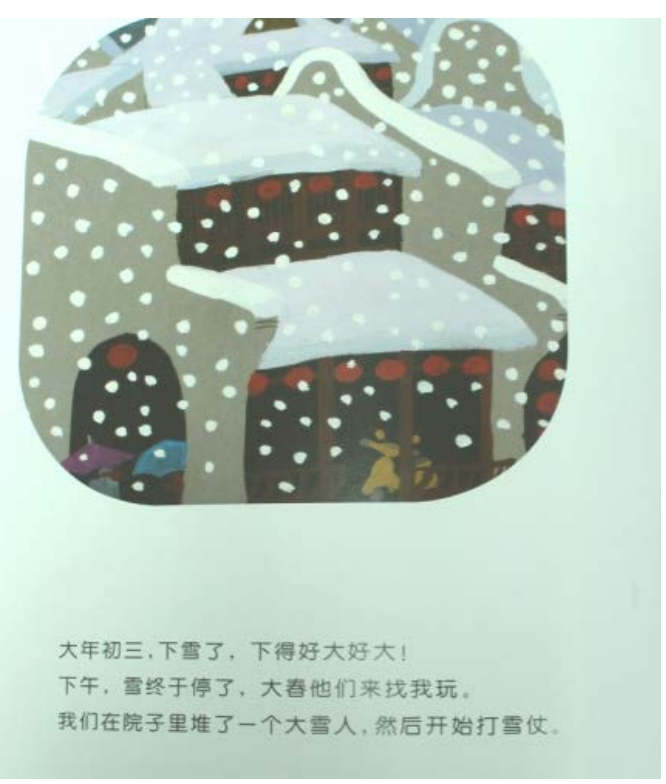

Figure 6. Chinese description of the snow.

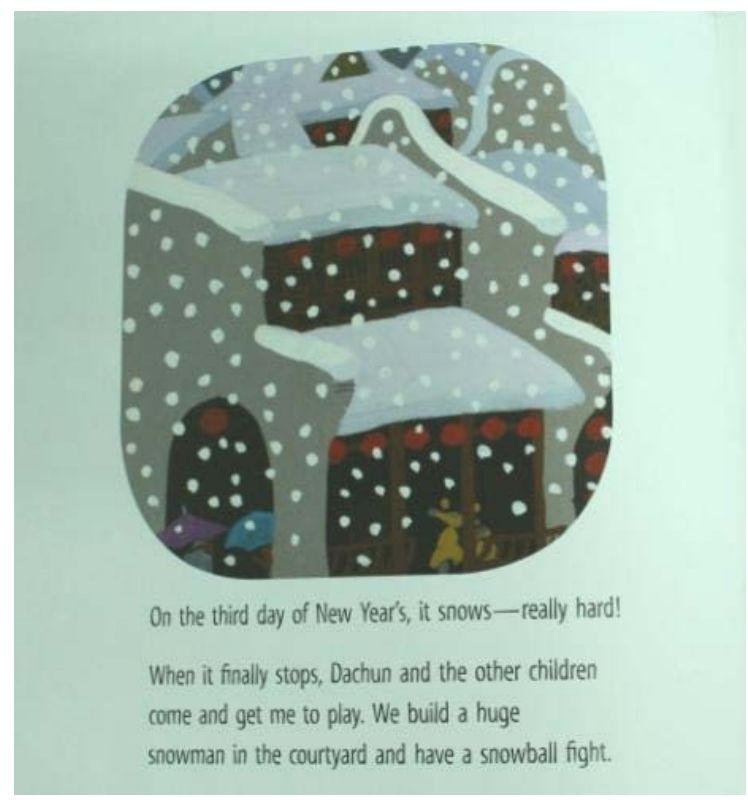

Figure 7. English description of the snow.

\subsubsection{Excelling at Layout}

The Red Shoe of Tang Sulan's Picture Book Series (All Eight Volumes) is characterized by its unique layout, which gives a childish flavor to the work. The distinctive layout of words can not only express the meanings of the original but also ensure that readers are aesthetically entertained. After finishing translating the text, the translator places the text in various ways like the source text according to the whole story. Some words are laid out as per the image of one protagonist, and others may be personified as two people talking. Such a novel layout plays a critical role in stimulating the innocent reader's interest. There is a scene in the story where the red shoe has difficulty in falling asleep after follow- 
ing the little mouse back to its home because the red shoe misses the other shoe (Figure 8). When translating the dialogue between the red shoe and the little mouse, the translator uses layout different from other sections in the picture book. Different English letters with the same font size form different words and they are indented line by line. The translated words look like notes of a beautiful song, and the whole layout creates a harmonious atmosphere (Figure 9).

In another scene, for instance, the little mouse and the red shoe rushes together and sing songs along the way, but they have no idea that their beautiful songs have already been passed to the big black cat ears, which indicates that there is still a certain distance between them and the big black cat. The translation here is also worthy of attention.

When translating " $\mathrm{Da}$ da da da", the translator not only simulates the beating of the notes through the overall line of the text but also places the text between the red shoe and the house where the big black cat lives, suggesting there is still a certain distance between them. This kind of creative arrangement echoes the panic of the little mouse in the following story and gets readers visually entertained as well (seeing Figure 10).

The two red shoes speak "I miss you" in a whisper to express their longing for each other on the shoe rack after they meet again. In the original, the author modifies the shape, color, and size of the font to accentuate emotions (seeing Figure 11). In the course of translation, the advantages of English have been brought into full play. As far as the language is concerned, the font with red color, bigger size, and round appearance is employed as well. The soft lines of the font are prone to evoke a sense of warmth and intimacy (seeing Figure 12).

From the perspective of visual impact, words of two shoes are drawing closer and closer, inferring that two shoes have never stop missing each other no matter how far they are apart. Obviously, the translation would be inferior to the

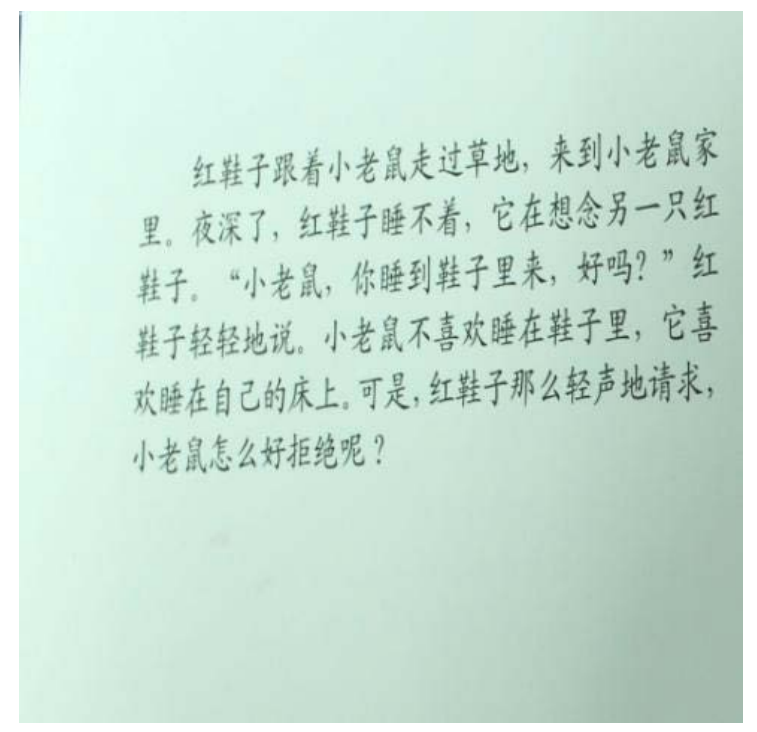

Figure 8. Chinese version of the dialogue between red shoe and mouse. 


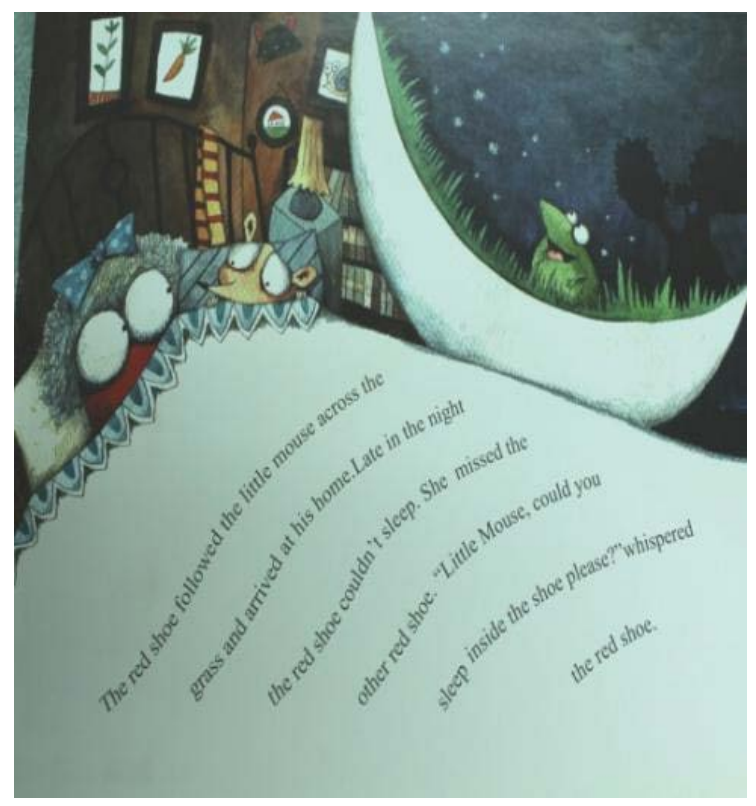

Figure 9. English version of the dialogue between red shoe and mouse.

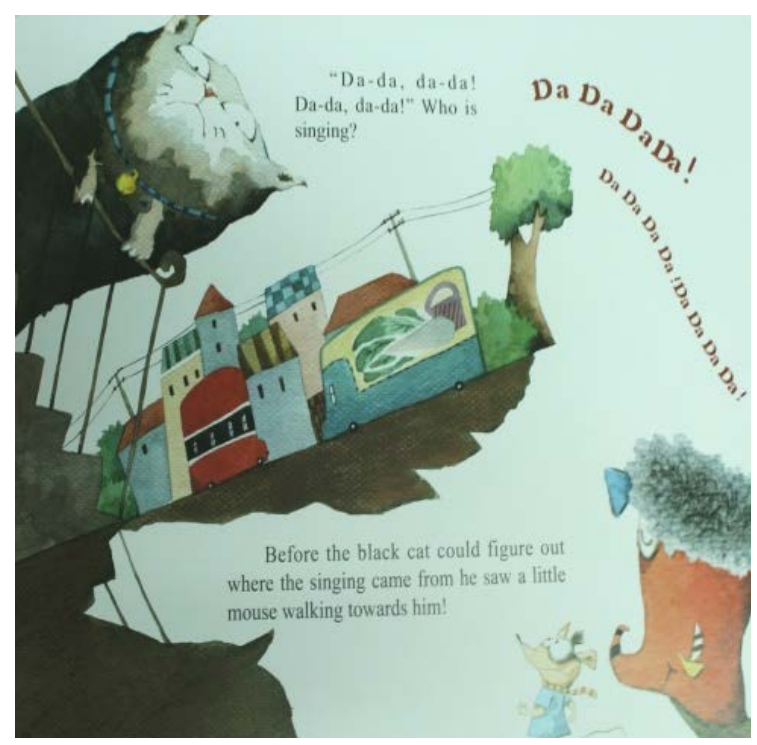

Figure 10. The song of the red shoe.

original from an aesthetic perspective if no alteration had been made in the font and layout. Liu Xing says that "the binding and design of the book refer to the whole design process of a book. It is a comprehensive presentation of the book content by using artistic techniques, including paper materials, binding, cover, color, layout, font, typography, illustration, and printing. And it is a kind of visual art" (Liu Xing 2007: 46, my own translation) [7]. Suffice it to say that the picture book with diversified layouts will surely become more popular among readers in the coming years since it is so artistic and interesting that it can satisfy children's curiosity. Therefore, during the translation of the original Chinese 


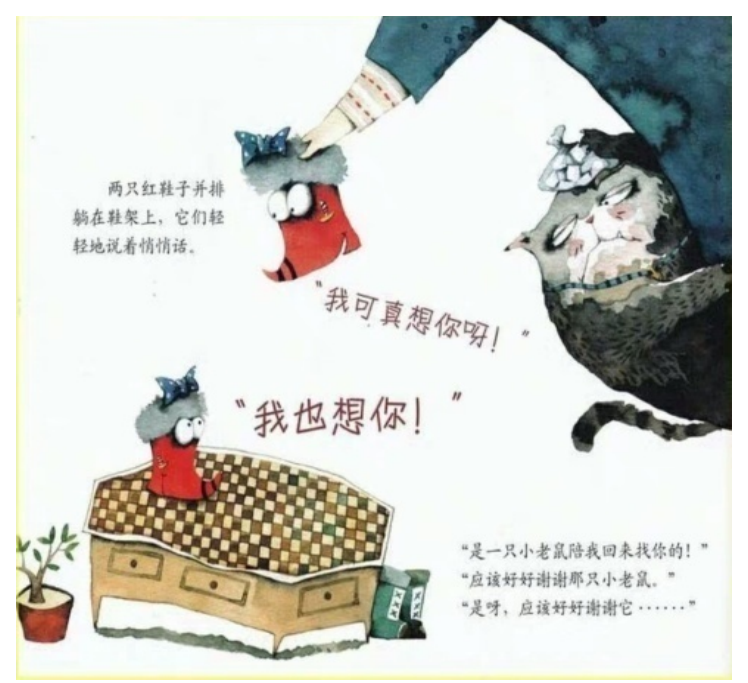

Figure 11. The Chinese version of two shoes' reunion.

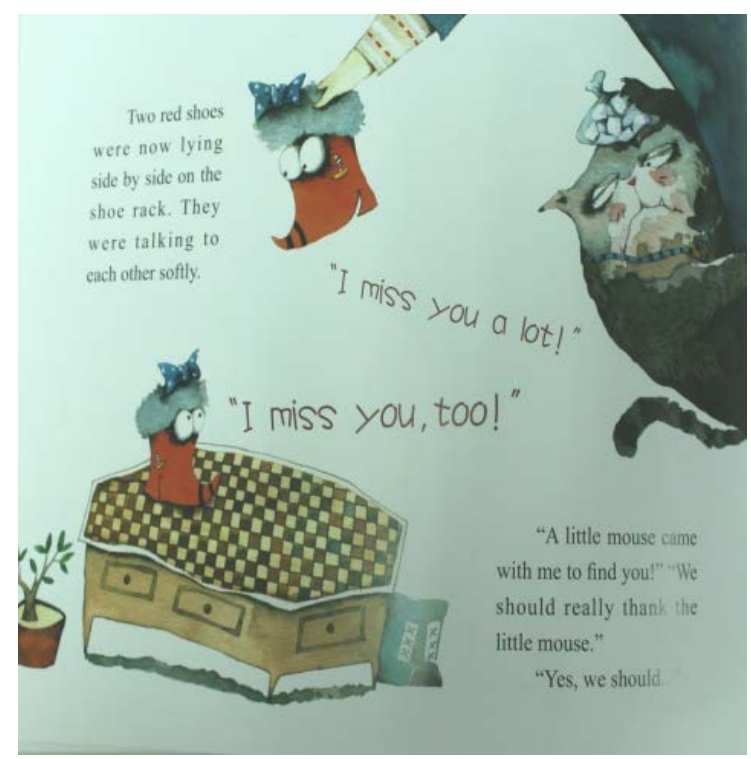

Figure 12. The English version of two shoes' reunion.

picture book, it is necessary for the translator to make use of the advantages of different layouts to attract and entertain young readers.

\subsection{Keeping Target Audience into Mind}

\subsubsection{Sharing and Presenting Childish Delight Dynamically}

Visual images in the children's picture books do not refer to pictures only. Furthermore, they also include visual elements such as print of the text, different shape and size of the font, making the translation more dynamic. In addition, indicated by those visual elements, readers can judge when should they read fast and when they should have a pause while reading and so on. Since the picture book is often created for young children, the author tends to use discourse fillers and reduplication to express happiness, sorrow, surprise, and other emotions so 
as to cater to the mentality of young readers.

While translating, the translator should bear target readers in mind and spare no effort to make the translation is equivalent to the original in the tone through various means like transforming the size or color of the font, highlighting important words in bold type and changing punctuation or using a line break. Only in this way can the translator present readers a piece of work full of dynamism and emotion.

For another example, double quotations are used in the original when there is a description of the rattle of the firecrackers so as to add to the gaiety of the festival (seeing Figure 13). In the translation, the translator repeats words "pop" and "bang" three times in an italic font and enlarges them with bold type, creating a lively and vivid environment of Chinese New Year for the whole story (seeing Figure 14). From Zhang Delu's viewpoint, "italics, as a form of graphology, can emphasize important components and have the same effect as the accent in the phonological system" (Zhang Delu 2005: 209, my own translation) [8]. Moreover, the translation, along with repetition, stands in a single line, not only making the translation more readable but also echoing the description of the successive rattle of fireworks in the original.

For another example, as is stated above, Maomao is not in the mood for sleeping because she fails to find out the lucky coin after a snowball fight. However, all of a sudden, there's something falling on the ground with a jingle when Maomao undressed. At that time, it suddenly comes to her that she does not lose the coin given by her beloved father. The jingle of the lucky coin implies the mood of Maomao is on the turn, namely from sadness to excitement and relief. The deep love between the father and the innocent daughter revealed by this coin touches readers deeply. In the original, the author lays emphasis on the

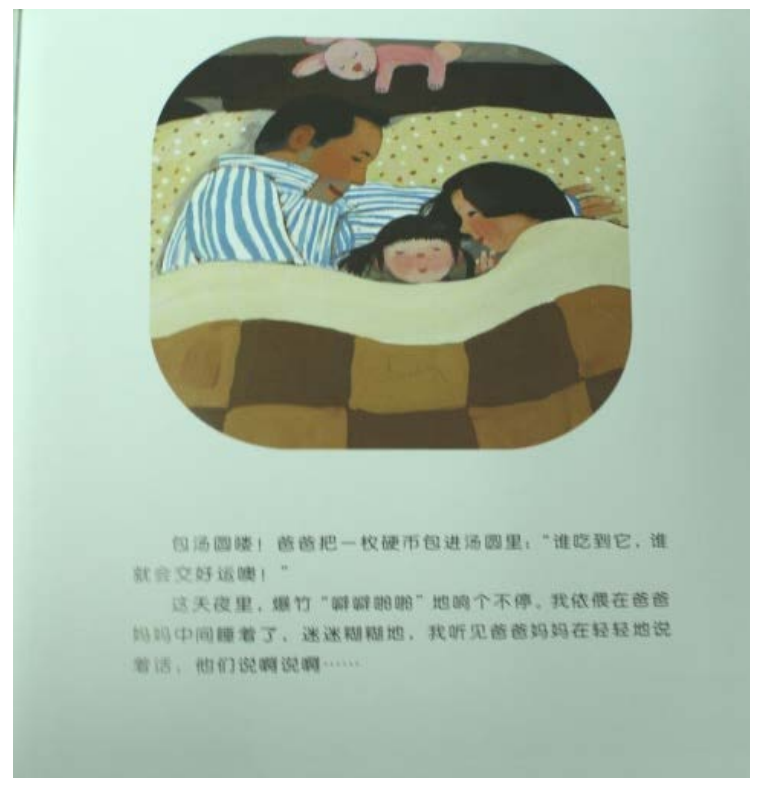

Figure 13. The Chinese description of crackle of fireworks. 


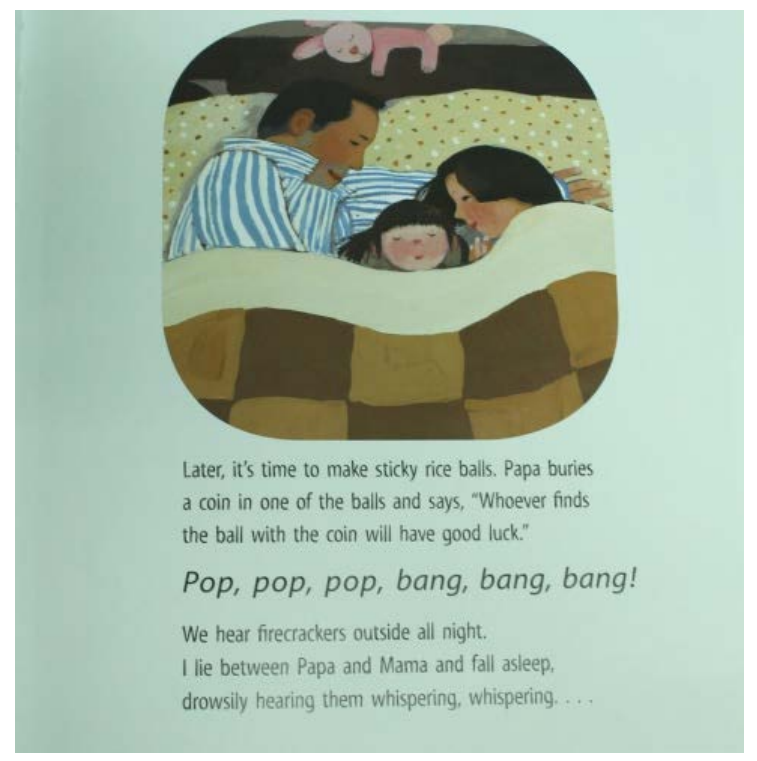

Figure 14. The English description of crackle of fireworks.

word "clink" by using double quotations and the dash before it. Being aware of its importance in the development of the story, the translator seeks new ways to stress the word "clink" based on the good command of two languages. In the translation, it is expressed in bold and an italic type (seeing Figure 15).

In addition, the translator changes the comma of the original into exclamation mark dexterously, which plays a critical role in underscoring mood change of Maomao and accords with the emotion expressed by the original. Means used by the translator thereby perform the interpersonal function, functioning as a way of silent communication between Maomao and her father. Accordingly, in view of differences between Chinese and English, grasping connotations of different punctuation in different languages and putting it into full use is vital in translating the picture book.

Time flies. The Spring Festival is drawing on, and the father's departure is around the corner for the sake of supporting the family. At the time of departure, the father asks Maomao if she likes dolls and promises her that he will bring her beautiful dolls next time. At the same time, young as Maomao is, she appreciates her father and loves him very much. Therefore, she is going to give the fortune coin to her father, showing her love and blessing to the father (seeing Figure 16).

In the translation, words "OK" and "you" symbolize the father's promise to her, and thick type is used for printing words "OK" and "you" so as to underline their reluctance to separate and expectation of reunion, which helps arouse the resonance of the readers' emotion (seeing Figure 17). As professor Zhao Xiuming says, "Each author has his own reflections on life and distinguishes himself by his own style in writing and using language. The translator has to grasp these factors during reading and translation. Only in this way can 'distinctive flavor of the original' be conveyed" (Zhao Xiuming 2002: 55, my own translation) [9]. 


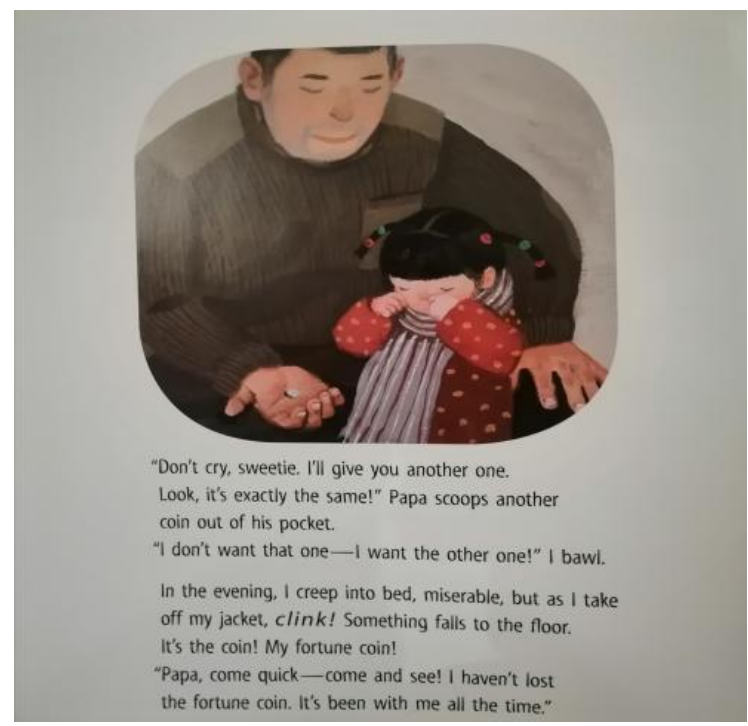

Figure 15. The reappearance of the fortune coin.

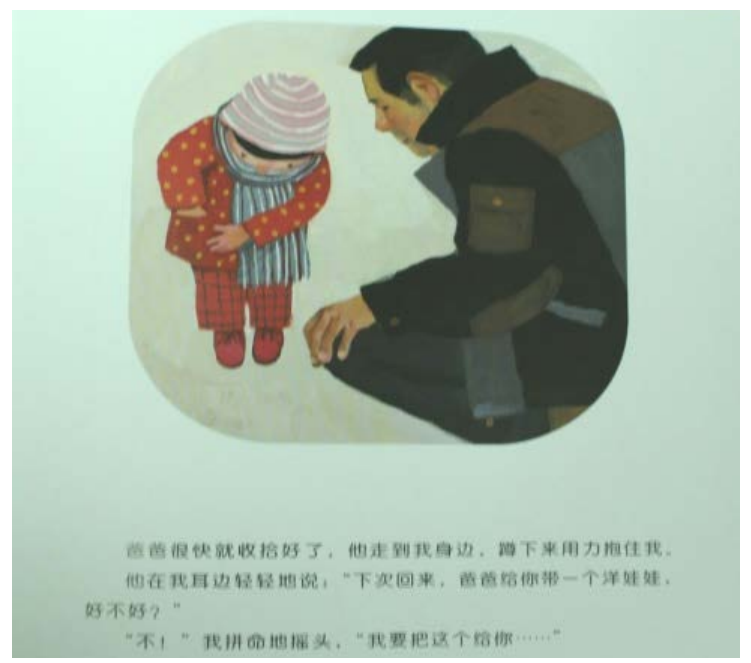

Figure 16. The Chinese description of the moment of parting.

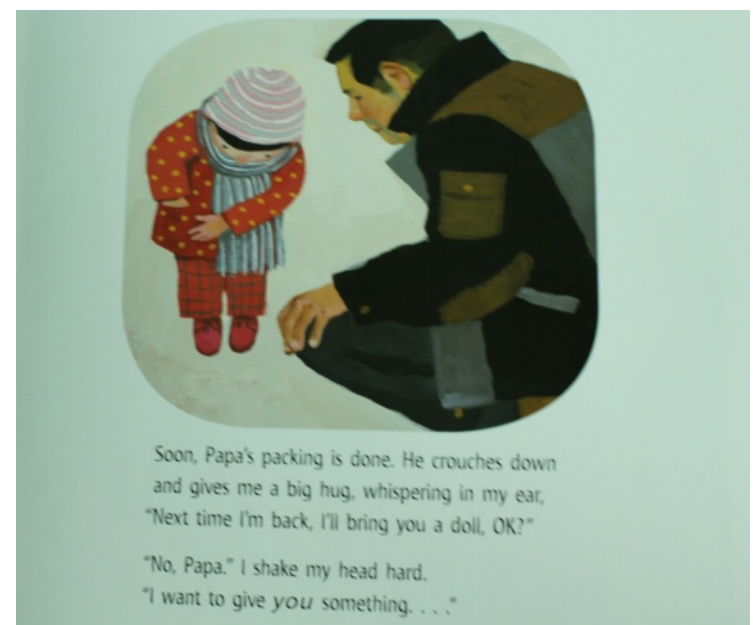

Figure 17. The English description of the moment of parting. 
In addition, the expression "Na jiu shi guo nian" emphasizes Maomao can only stay with her father during Chinese New Year (seeing Figure 18). Generally speaking, it is acceptable to use the emphatic pattern to express the emotion of the original. Suffice it to say, the original text can be translated as "It is only during Chinese New Year that he comes home". However, had the translator dealt it with the emphatic pattern, the translation would have confused the audience since the picture book is usually created for young children who are too young to understand the emphatic pattern. On the contrary, the line break is adopted here by the translator. The phrase "during Chinese New Year" is placed in another line to draw readers' attention, and the two sentences are both ended with the word "year", making the translation is more readable (seeing Figure 19).

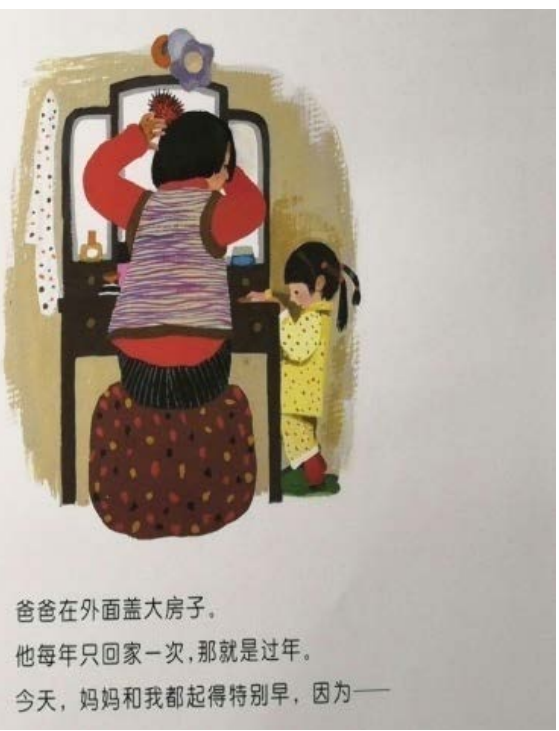

Figure 18. The Chinese description of the father's return.

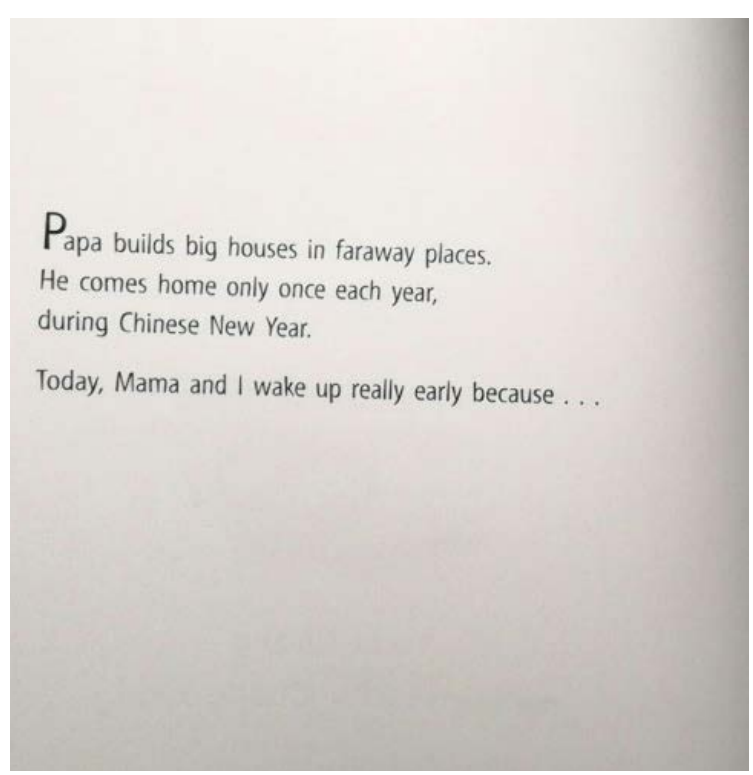

Figure 19. The English description of the father's return. 
All in all, in the process of translating original picture books, it is imperative that the translator keeps the audience into mind because only in this way, the audience is willing to read stories.

\subsubsection{Reproducing Childish Delight}

The picture book, a kind of gripping read for young readers, is ordinarily read to children by adults. Thanks to this feature, the picture book rich in rhythm and rhyme is likely to reach a wider audience, namely both children and parents. "The translator translating for children should pay attention to this usage of children's literature and remember that a child under school age listens to texts read aloud, which means they should live, roll, and taste good on the reading adult's tongue." (Oittinen 2000: 32). To this end, in English translation of Chinese original picture books, simplicity and readability should never be ignored. The translator can omit repeated parts or translate with short sentences in the interest of rhythm. Moreover, methods such as figures of speech and restructuring of sentences are conducive to the formation of rhyme.

The translation of First Trip away from Home, one of eight volumes, sets a fine example. When depicting the scene where Mummy Koala finds Baby Koala, the author forwards the plot with four short sentences (seeing Figure 20).

However, as is known to all, Chinese is characterized by parataxis, while English is featured by hypotaxis. Abiding by English grammar, the translator adds "he" as the subject in the first short sentence. Nevertheless, the subject and predicate are all left out in the light of the context and simplicity. And anxiety comes to light after reading sentences aloud (seeing Figure 21).

Figures of speech and rhyme have a part to play in ensuring that readers will be aesthetically entertained. For instance, there are expressions like "An injured

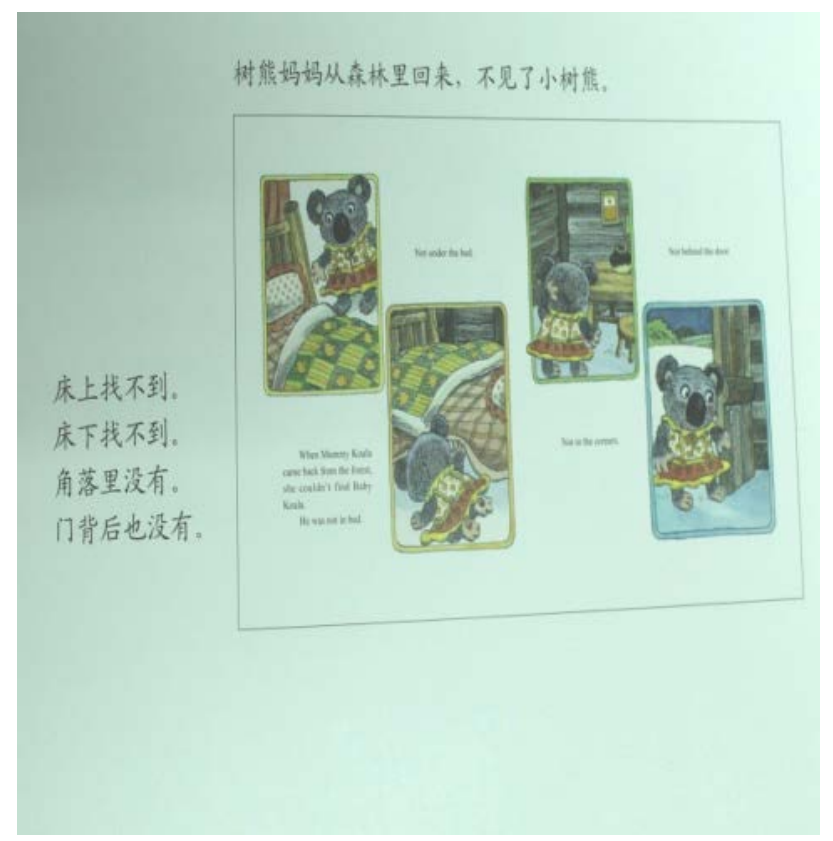

Figure 20. The Chinese description of the search for Baby Koala. 


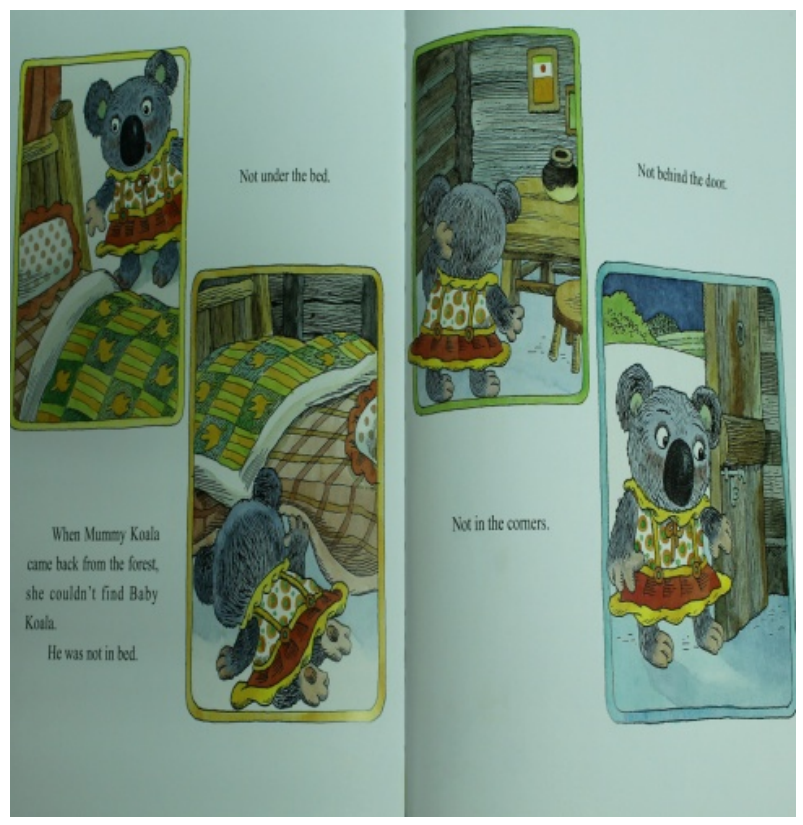

Figure 21. The English description of the search for Baby Koala.

hare ran across and fell on the grass" and "Baby Koala spoke in a very loud voice, with eyes wide open and staring at the fox". After reading aloud, it can be known that "across" rhymes with "grass" and "voice" rhymes with "fox".

This kind of translation not only makes the story more literary but also inclines to entertain readers and listeners at the same time, which tends to attract a much wider audience.

\subsection{Paying Full Attention to Interaction between Culture and Translation}

When a language is converted into another language, it is impossible to find a completely equivalent expression to convey the meaning, especially some proper nouns, idioms, proverbs, proverbs, and allusions because they are endowed with specific meanings in a certain culture. As Wang Zhiguo, a distinguished scholar who dedicates himself to studying the Chinese Ethnic Minority Literature which involves various cultures, says, "for the lack of background knowledge about culture of source language, how to make audiences of target language feel they are reading the original has always been the topic of translation studies and the pursuit of excellent readers" (Wang Zhiguo 2016: 33, my own translation) [10].

This phenomenon occurs in the translation of Chinese original picture books as well which serve as the carrier of Chinese cultures.

In western countries, however, it is Christmas that carries a similar emotion. The translator, therefore, takes culture into account and translates the title into "A New Year's Reunion", which makes the theme of the original clear to the target audience. What's more, the cover of the picture book is also altered in order to conform to western culture (seeing Figure 22 and Figure 23). In the original, Maomao and her parents are sleeping together, which is common for Chinese. 


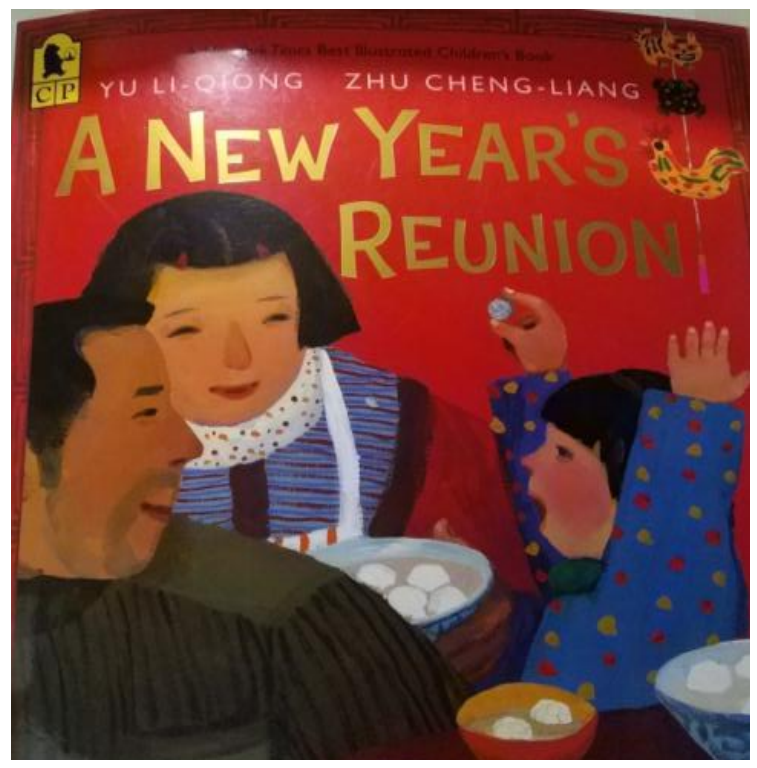

Figure 22. The cover in the English version.

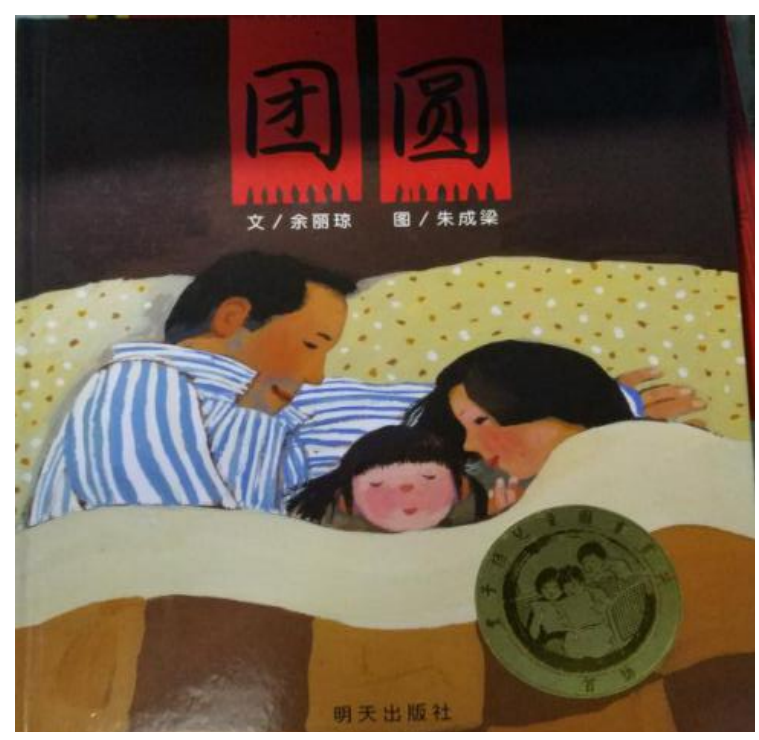

Figure 23. The cover in the Chinese version.

However, individualism is attached to great importance in western countries and children sleep alone since they are very young. Therefore, in the English version, the cover is replaced with the scene where Maomao is having sticky rice balls and finds the lucky fortune.

When translating picture books of this kind, the translator can add some annotations to the difficult points, or find the expression in the target language that matches the connotations conveyed in the original. The translation of the title of A New Year's Reunion is worthy of note. The title of the original is "Tuan yuan" in Chinese. If it is translated into "Reunion", it seems to be loyal to the original. However, the spirit of the original disappears, because in this story, it refers to the reunion in Spring Festival in China, which is familiar to Chinese readers. 
In sum, "in translation, it may usually be expected that a marked item in the ST would be translated by a similar item in the TT but this is not always so" (Munday 2016: 99) [11]. Therefore, the factor of culture can never be neglected in the process of the English translation of Chinese original picture books, and the translator should do his best to compensate for the meaning difference caused by culture.

\section{Conclusions}

Based on the previous analysis in this paper, it is proved that multimodal discourse analysis is applicable to and important for the analysis of Chinese original picture books. It can be seen that English translation of original picture books can be realized from three dimensions, namely taking both texts and pictures and their interaction into full account, making it possible for readers to enjoy themselves during reading, and showing great respect for cultural differences. The translator must not only have a good ability to scrutinize pictures but also abide by the following principles, namely choosing words on the basis of precise interpretation of pictures, giving priority to the context, considering both pictures and text, and excelling at the layout. Besides, the translator should bear readers into the mind and strive to entertain readers aesthetically by means of reproducing childish delight and presenting it dynamically. Last but not least, respecting cultural differences is also a must. The translator of Chinese original picture books is supposed to contrive to make the translation loyal to the original not only in content level but also in cultural level in various ways. However, multimodal nature of original picture books demands more abilities. In addition to a good grasp of both source language and target language, the command of art and design is also a must. Therefore, as pictures are open to interpretation, insufficient knowledge about art and design may make the study be tinged with a little subjectivity.

The cultural creativity of a nation is reflected by its outstanding works of literature and art. Numerous Chinese children's books are published every year, with an increasing number of picture books. As the overarching part of children's literature, the picture book distinguishes itself from others by its multimodality. In an era when cultural soft power plays a vital role in the development of one country, Chinese original picture books, endowed with substantial Chinese elements, shoulder the responsibility to tell Chinese stories and to deepen foreigners' understanding of China. Under the circumstances, the translation of Chinese original picture books is a significant move in the inheritance and transmission of fine Chinese culture. Although Chinese original picture books have not yet entered the mainstream market of children's literature in the world, with the deep cooperation between translators, illustrators, and publishers, Chinese original picture books containing Chinese culture and Chinese elements will surely attract more audience. Composite national strength will grow much stronger as more and more Chinese original picture books are going global. 


\section{Conflicts of Interest}

The authors declare no conflicts of interest regarding the publication of this paper.

\section{References}

[1] 李战子. 多模式话语的社会符号学分析 [J]. 外语研究, 2003(5): 1-8+80.

[2] Kress, G. and Van Leeuwen, T. (2006) Reading Images: The Grammar of Visual Design. 2nd Edition, Routledge, London.

[3] 朱永生. 多模态话语分析的理论基础与研究方法 [J]. 外语研究, 2007(5): 82-86.

[4] Oittinen, R. (2000) Translating for Children. Garland Publishing, Inc., New York, London.

[5] Newmark, P. (1981) Approaches to Translation. Pergamon, Oxford and New York.

[6] Lawrence, R.S. (1998) How Picture Books Work: A Semiotically Framed Theory of Text-Picture Relationships. Children's Literature in Education, 29, 97-108. https://doi.org/10.1023/A:1022459009182

[7] 刘星. 从儿童审美偏爱看儿童书籍的装帧设计[J]. 编辑学刊, 2007(3): 46-49.

[8] 张德禄. 多模态话语分析综合理论框架探索[J]. 中国外语, 2009, 6(1): 24-30.

[9] 赵秀明. 文学翻译的“韵味”说一一论刘士聪的文学翻译理论与实践 [J]. 外语与外 语教学, 2002(12): 53-56.

[10] 王治国. 西方藏学对《格萨尔》的深度描写与文化翻译一一达维.妮尔英译本的民 族志阐释 [J]. 民族文学, 2016(2): 30-34.

[11] Munday, J. (2016) Introducing Translation Studies. Routledge, London.

\section{Appendix}

Picture books involved in this thesis:

Tang, S.L. and Fei, J. (2016) First Trip away from Home. Hunan Juvenile and Children's Publishing House, Changsha.

Tang, S.L. and Wang, K. (2016) The Red Shoe. Hunan Juvenile and Children's Publishing House, Changsha.

Yu, L.Q. and Zhu, C.L. (2013) A New Year's Reunion. Candlewick Press, Somerville. 余丽琼, 朱成梁. 团圆 [M]. 明天出版社, 济南, 2008. 